\title{
CULTURA MATERIAL, ESPAÇOS E EDIFÍCIOS ESCOLARES NA REVISTA DE PEDAGOGÍA/ESPANHA: A CIRCULAÇÃO DAS IDEIAS INTERNACIONAIS E O CONTEXTO ESPANHOL (1922-1934) ${ }^{1}$
}

DOI: http://dx.doi.org/10.1590/2236-3459/67532

\author{
Tatiane de Freitas Ermel \\ Pontifícia Universidade Católica do Rio Grande do Sul, Brasil.
}

$\cos 80$

\begin{abstract}
Resumo
Neste estudo é analisado um conjunto de 20 artigos da Revista de Pedagogía, Espanha, publicados entre os anos 1922-1934, que abordam os temas relacionados aos espaços, edifícios escolares e ao mobiliário escolar. O periódico, fundado e dirigido por Lorenzo Luzuriaga entre os anos de 1922-1936, era destinado especialmente para professores, diretores, inspetores, professores de institutos e universitários. Constatamos que os artigos apresentam concepções internacionais relacionadas às novas tendências dos espaços escolares, especialmente sobre as escolas ao ar livre e o mobiliário. Em relação ao contexto espanhol aborda-se as construções escolares e os investimentos materiais num intenso debate entre a necessidade de expansão para as regiões mais distantes do país e as construções monumentais dos grandes centros urbanos.

Palavras-chave: imprensa pedagógica, cultura material, edifícios escolares, espaço escolar, mobiliário escolar.
\end{abstract}

\section{MATERIAL CULTURE, SPACES AND SCHOOL BUILDINGS IN THE PEDAGOGY MAGAZINE/SPAIN: THE CIRCULATION OF INTERNATIONAL IDEAS AND THE SPANISH CONTEXT (1922-1934)}

\begin{abstract}
The study analyzes a set of 20 articles of Revista de Pedagogía, Spain, published between the years 1922-1934, that address the issues related to spaces, school buildings and school furniture. The periodic, founded and directed by Lorenzo Luzuriaga between the years of 1922-1936 was destined specially for teachers, principals, inspectors, institutes teachers and university professors. We verified that the articles present international concepts related to new trends in school spaces, especially about outdoor schools and the furniture. In relation to the Spanish context, discusses the school buildings and material investments in an intense debate between the need for expansion to the most distant regions of the country and monumental buildings of large urban centers.

Key-words: pedagogical press, material culture, school buildings, school space, school furniture.
\end{abstract}

${ }^{1}$ Este trabalho foi realizado com auxílio financeiro da Capes, processo número: 99999.005589/2014-02. 


\section{CULTURA MATERIAL, ESPACIOS Y EDIFICIOS ESCOLARES EN LA REVISTA DE PEDAGOGIA/ESPAÑA: LA CIRCULACIÓN DE IDEAS INTERNACIONALES Y EL CONTEXTO ESPAÑOL (1922-1934)}

\section{Resumen}

Este estudio analiza un conjunto de 20 artículos de la Revista de Pedagogía, España, publicados entre los años 1922-1934, que tratan de temas relacionados con los espacios, edificios y mobiliario escolar. La revista, fundada y dirigida por Lorenzo Luzuriaga, entre los años 1922-1936, estaba destinada, especialmente, a maestros, directores, inspectores, profesores de institutos y universitarios. Se constata que los artículos analizados presentan conceptos internacionales relacionados con las nuevas tendencias en los espacios escolares, sobre todo en las escuelas al aire libre y mobiliario escolar. En relación con el contexto español, aborda los edificios escolares y la inversión financiera, generando un intenso debate entre la necesidad de expansión a las regiones más distantes del país y de las construcciones monumentales de los grandes centros urbanos.

Palabras-clave: prensa pedagógica, cultura material, edificios escolares, espacio escolar, mobiliario escolar.

\section{CULTURE MATÉRIEL, ESPACES ET BÂTIMENTS SCOLAIRES DANS LE REVISTA DE PEDAGOGÍA/ESPAGNE: LA CIRCULATION DES IDÉES INTERNATIONALES ET CONTEXTE ESPAGNOL (1922-1934)}

\section{Résumé}

L'étude analyse un ensemble de 20 articles de Revista de Pedagogía, Espagne, publiés entre 1922-1934, qui traitent des thèmes relatif à l'espace, les bâtiments et du mobilier scolaires. Le périodique est fondé et dirigé pour Lorenzo Luzuriaga, entre les années 1922-1936, a été spécialement dirigé pour les enseignants, les directeurs, les inspecteurs, instituts et professeurs d'université. Nous considérons que les articles ont des concepts internationales relatifs aux nouvelles tendances dans les espaces scolaires, en particulier sur les écoles de plein air et les meubles. En ce qui concerne le contexte espagnol, aborde des bâtiments scolaires et l'investissement matériel dans un débat intense entre la nécessité d'une expansion vers les régions les plus lointain du pays et les bâtiments monumentales de grands centres urbains.

Mots-clé: presse pédagogique, culture matérielle, bâtiments scolaires, espace scolaire, mobilier scolaire. 


\section{Introdução}

imprensa de modo geral e, a pedagógica e de ensino de forma particular, tem
sido considerada, a partir dos anos 1970, um importante documento para
historiadores da educação ${ }^{2}$. Como um espaço privilegiado de circulação de ideias, análise e crítica dos processos políticos, culturais e educativos - dentro e fora das instituições - constitui um observatório para a compreensão da história da educação. De acordo com Bastos (2015)

os jornais, boletins, revistas, magazines - feitas por professores para professores, feitas por alunos para seus pares ou professores, feitas pelo Estado ou outras instituições, como sindicatos, partidos políticos, associações de classe, igrejas - contêm e oferecem muitas perspectivas para a compreensão da história da educação e do ensino. Sua análise possibilita avaliar a política das organizações, as preocupações sociais, os antagonismos e filiações ideológicas, além das práticas educativas e escolares. (p. 22)

Neste estudo, ainda acrescentamos a palavra científica, ou seja, a imprensa pedagógica científica, pode ajudar os historiadores da educação na construção de histórias particulares, dos professores, da ciência da educação, de instituições, centros de formação de professores, universidades, assim como sobre materiais de ensino, métodos de trabalhos, movimentos sindicais, dentre outras inúmeras maneiras e temas que podemos investigar (Hernández Díaz, 2013a).

A partir dessa abordagem analisamos um conjunto de 20 artigos da Revista de Pedagogia/Madrid, publicados entre os anos 1922-1934, problematizando como o periódico apresenta e discute as questões relativas aos espaços, edifícios, mobiliário e material escolar ${ }^{3}$. Fundado e dirigido por Lorenzo Luzuriaga ${ }^{4}$ entre os anos de 1922-1936, o periódico era destinado especialmente para professores, diretores, inspetores, professores de institutos e universitários.

\footnotetext{
${ }^{2}$ Hernández Díaz (2013a, p. 15-32) apresenta um importante levantamento e análise sobre a imprensa pedagógica na Europa e, especialmente na Espanha. Motilla e Gonzáles (2015) apresentam em seu artigo sobre o periódico El buen amigo uma interessante análise acerca dos estudos pioneiros da imprensa pedagógica na Espanha. Para mais informações, ver Motilla e Gonzáles (2015, p. 409-423).

3 A Revista de Pedagogía foi consultada no acervo do Museo de Historia de la Educación Manuel Bartolomé Cossío, Universidad Complutense de Madrid/Espanha, e na Biblioteca del Ministério de Educación, também em Madrid.

${ }^{4}$ Lorenzo Luzuriaga (Valdepeñas, 1889 - Buenos Aires, 1959), foi um pedagogo espanhol, com sua vida familiar estritamente ligada às questões pedagógicas como filho, sobrinho e irmão de professores. Discípulo de Bartolomé Cossío e Giner de los Rios, foi aluno e professor da Institución Libre de Enseñanza - ILE - entre 1908 e 1912. Em 1913-1914 recebe bolsa para estudar na Alemanha e quando regressa a Espanha, segue sua vida como funcionário, professor e publicista, realizando esporadicamente visitas ao exterior para proferir conferências e assistir congressos. A partir de 1915 temos sua aproximação e militância socialista, que será paralelamente impulsionado pela instituição "La escuela Nueva". Entre 1914 e 1921 se confirma a trajetória seguida por Luzuriaga com a política e a educação, demostrando suas preocupações com a com a ação educativa e pedagógica como colaborador no semanário España e sua continuação em El Sol (1917-1921), temas que alcançam seu máximo desenvolvimento na Revista de Pedagogía (1922-1936). Exilado na Argentina, foi professor de Pedagogia nas Universidades de Tucumán e Buenos Aires. Para análise mais ampla sobre a biografia e trajetória profissional, ver Barreiro (1989).
} 
Segundo Hernández Díaz (2013b), ao analisar a imprensa pedagógica e suas modalidades, um primeiro campo semântico e hermenêutico está relacionado com o mundo associativo dos professores, parte central da atividade escolar desde o despertar de um sistema nacional de educação:

La prensa pedagógica acoge los problemas y reclamaciones de sus profisionales (principalmente maestros y profesores de los distintos niveles del sistema escolar), pero también si convierte en vehículo informativo de diferentes asuntos educativos de interés legislativo, asociativo, científico, metodológico, del ultillaje escolar, de libros y manuales de interés para mejor ejercicio de la profesión de maestro o de docente en la enseñanza secundaria o en la universidad. (p. 22)

Em linhas gerais a Revista de Pedagogía abordava aspectos sobre renovação, reformas e melhoras das escolas, fortemente influenciados pelo movimento da Escola Nova ${ }^{5}$. Também estava marcada por movimentos e organizações de intelectuais espanhóis como a Institución de Libre Enseñanza ${ }^{6}$, Museo Pedagógico e a Junta para Ampliación de Estudios, com a Residencia de Estudiantes e Instituto Escuela. Contava com a participação de reconhecidos colaboradores estrangeiros, como Cousinet; Decroly; Claparéde; Kerchensteiner; Dewey; Kilpatrick; Ferriére, Montessori e Piaget, chegando a alcançar a tiragem de 4.000 exemplares no ano de 1933 (López; Delgado, 2014).

A partir desse breve adentrar à imprensa pedagógica consideramos a Revista de Pedagogía um importante documento para uma análise da história da educação desde uma perspectiva global e local, ou seja, a partir da circulação de ideias e modelos internacionais ao mesmo tempo que nos traz informações do contexto espanhol, destacando suas particularidades regionais.

\section{Os espaços e a materialidade escolar}

Dentro da perspectiva da cultura e da materialidade escolar selecionamos na Revista de Pedagogía uma série de artigos relacionados aos espaços, arquitetura, mobiliário e material escolar. Os estudos sobre o tema têm contribuído para avançar a ideia de que os espaços escolares não são neutros, ou seja, necessitam ser compreendidos a partir de seus significados e representações (Viñao, 1998).

Os espaços educativos têm sido constantemente discutidos no panorama internacional, sendo tema da última Jornada da Sociedad Española para el estúdio del Patrimonio Historico-Educativo - Sephe -, celebrado em de 2016, em Donostia-San Sebastían/Espanha. Autores espanhóis, como Trilla (1999), Viñao Frago (1993-94, 1996, 1998, 2005), Agustín Escolano $(1993-94,1998,2000)$ têm contribuído para reflexões nesse âmbito, apresentando e discutindo o conceito de espaço e arquitetura escolar para a Europa mediterrânea e estabelecendo constantes diálogos com a América Latina ${ }^{7}$.

Outros pesquisadores no contexto europeu têm sido importantes para as reflexões e difusão dessas pesquisas como, por exemplo, Chatêlet $(1999,2003,2006)$ na França; Silva $(2002,2005,2009,2015)$ e Felgueiras $(2009,2008,2007,2006)$ em Portugal,

\footnotetext{
${ }^{5}$ Para uma análise mais ampla sobre a Revista de Pedagogía (1922-1936) Mérida Nicolich (1983a; $\left.1983 b\right)$.

${ }^{6}$ Para uma análise sobre a Institución Libre Enseñanza e arquitetura escolar ver Rodriguez Méndez (2004, 2007).

${ }^{7}$ Ver Viñao Frago; Escolano (1998). 
Fossati (2014), na Itália; Burke; Grosvenor (2008), analisando o contexto da Europa ocidental; Braster; Grosvenor; Pozo (2011), englobando distintas experiências e abordagens acerca da cultura material em sala de aula. No Brasil, podemos citar importantes contribuições, como Faria Filho e Vidal (2000), Faria Filho (2000, 2015); Baltar (2001), Buffa e Pinto (2002), Bencostta (2005, 2007), Wolff (2010).

A partir dos estudos acerca dos espaços escolares consideramos a arquitetura como um dos elementos materiais que mais sobrevive ao tempo e que constitui por si mesma um programa, uma espécie de discurso que institui em sua materialidade um sistema de valores, como os de ordem, disciplina e racionalidade, um dos marcos para a aprendizagem sensorial e motora e toda a semiologia que cobre diferentes símbolos estáticos, culturais e também ideológicos (Escolano, 2000, p. 183). Apesar de um elemento visível, implícito ou manifesto, constitui-se numa forma oculta, invisível e silenciosa de inculcar, transmitir, produzir e reproduzir valores, formas de ser aluno, criança e futuro cidadão.

Os espaços e o edifício escolar, em seu conjunto, não só realizam seu conteúdo educativo ao apresentarem funções que devem ser acolhidas pelos estudantes, pais, professores, como também exercem uma função diretamente formativa. Os lugares formam, ou deformam, seus usuários e, portanto, a arquitetura enquanto cumpre sua função como arquitetura também cumpre em primeiro nível sua função como pedagogia (Trilla, 1999).

O final do século 19 e as primeiras décadas do 20 são marcados por um intenso debate sobre os problemas causados pela adaptação de casas e outros espaços para atividades escolares e a necessidade de prédios projetados e construídos para serem escolas. Esse discurso perpassa fronteiras nacionais e, com menor ou maior grau de desenvolvimento, está presente na maioria de países europeus e americanos. As conferências pedagógicas também abordam as questões relativas a esse tipo de construção, sendo responsáveis pela circulação de ideias e projetos. Como símbolo emblemático da modernidade educacional as exposições, congressos pedagógicos assim como em missões de estudos de professores, visavam a divulgar as novidades no âmbito internacional. Principalmente os Estados Unidos e a Europa ${ }^{8}$ serviam de modelo para a instrução pública dos países considerados atrasados ou menos desenvolvidos ${ }^{9}$.

A maioria dos artigos analisados neste estudo foi publicado nas sessões intituladas Notas del mes e Informaciones, sendo que o número de reportagens mais significativo é sobre edifícios e construções escolares, com 12 artigos. Depois o material e mobiliário e ambiente e espaço escolar, com 5 e 3 artigos respectivamente. Para fins de organização partiremos do mais amplo ao mais específico, analisando aqueles que apresentam a questão do espaço ou ambiente escolar, depois os que tratam dos edifícios e construções e, por fim, os que abordam o material e mobiliário.

\footnotetext{
${ }^{8}$ Para o caso da França ver Matasci (2015).

${ }^{9}$ Sobre as exposições universais ver Pesavento (1997), Kuhlmann (2001), Warde (2002). Sobre a primeira exposição do Rio de Janeiro ver Bastos (2005). 
Quadro 1 -

Artigos na Revista de Pedagogía/Espanha (1922-1934) ${ }^{10}$.

\begin{tabular}{|c|c|c|}
\hline Número/ano & Título & Autor \\
\hline 12/dez.1922 & $\begin{array}{l}\text { Clases aireadas, escuelas al aire libre } \\
\text { preventoriums }\end{array}$ & Informaciones \\
\hline 29/mai.1924 & El material escolar & Notas del mes \\
\hline 29/mai.1924 & La construcción de edificios para escuelas & Notas del mes \\
\hline 35/nov.1924 & El mobiliario pedagógico & Notal del mes \\
\hline 46/out.1925 & $\begin{array}{l}\text { Materiales y métodos de la nueva } \\
\text { educación }\end{array}$ & Informaciones \\
\hline 58/out.1926 & Los edificios escolares de España & Informaciones \\
\hline 85/jan.1929 & La escuela al aire libre & Sensat, Rosa \\
\hline 92/ago.1929 & Las construcciones escolares & Nota del mes \\
\hline 99/mar.1930 & Construcciones escolares & Lanera, Juan \\
\hline 99/mar.1930 & $\begin{array}{l}\text { El mobiliario escolar movible" en los } \\
\text { Estados Unidos }\end{array}$ & \\
\hline 105/set. 1930 & Las construcciones escolares en España & Manrique, Gervasio \\
\hline 119/nov.1931 & La creación de 7000 escuelas & Notas del mes \\
\hline 129/set.1932 & $\begin{array}{l}\text { Cuatrocientos millones para edificios } \\
\text { escolares }\end{array}$ & Notas del mes \\
\hline 131/nov.1932 & El material de enseñanza & Informaciones \\
\hline 134/fev.1933 & Las construcciones escolares & Notas del mes \\
\hline 138/jun.1933 & La escuela y el medio ambiente & Luziriaga, Lorenzo \\
\hline 138/jun. 1933 & $\begin{array}{l}\text { Los edificios escolares como factor } \\
\text { educativo }\end{array}$ & Informaciones \\
\hline 143/nov. 1933 & $\begin{array}{l}\text { El problema del entretenimiento de los } \\
\text { edificios escolares }\end{array}$ & Notas del mes \\
\hline 145/jan.1934 & La arquitectura rural escolar & $\begin{array}{ll}\text { Vías } & \text { Sáenz-Diez, } \\
\text { Manuel } & \end{array}$ \\
\hline 152/ago.1934 & Las construcciones escolares & Vías Manuel \\
\hline
\end{tabular}

De um modo geral as reportagens apresentam as concepções internacionais relacionadas às novas tendências dos espaços escolares, especialmente sobre as escolas ao ar livre e o mobiliário. Em relação ao contexto espanhol aborda, quantitativamente e qualitativamente, as construções escolares e os investimentos materiais num intenso debate entre a necessidade de expansão edifícios escolares para as regiões mais distantes do país e as construções monumentais dos grandes centros urbanos. Outro aspecto importante consiste nos modelos do mobiliário escolar, que deveria ser adaptável e flexível à realidade do aluno e não estar restrito a um modelo padronizado pelo governo nacional. Ainda, traz temas como arquitetura rural, manutenção e higiene dos edifícios escolares, a escola e o meio ambiente.

\footnotetext{
${ }^{10}$ Cabe assinalar que não há imagens nos artigos analisados. Desse modo optou-se por não acrescentar de outras fontes que desempenhariam uma função meramente ilustrativa. 


\section{Espaço e ambiente escolar}

$\mathrm{Na}$ seção de Informações temos as considerações e recomendações do Primeiro Congresso Internacional de escolas ao ar livre, celebrado em Paris, no ano de 1922. Apresenta definições como de aula arejada, que consiste em uma sala com janelas dos dois lados que estão permanente abertas; de escola ao ar livre, que seria uma instituição construída fora da cidade em boas condições de exposição, para crianças não tuberculosas, que pode ser concebida como externato ou internato ${ }^{11}$; os preventoriums, que consistem em estabelecimentos situados no campo e onde crianças com doenças curáveis são submetidas a um regime de internato com higiene especial, com colaboração de um médico e pedagogo. Finalmente, apresenta as 19 resoluções tomadas no congresso que consistem basicamente no estímulo, organização, financiamento das escolas ao ar livre e o desejo que se criem comitês nacionais em diferentes países para estudo e resolução das questões médico-pedagógicas (Revista de Pedagogía, n. 12, 1922, p. 470-472).

Sobre a mesma temática Rosa Sensat ${ }^{12}$ destaca a importância da relação entre indivíduo e meio, utilizando como exemplo a Escola de Bosque Montjuich, Barcelona/Espanha. Apresenta alguns questionamentos: como o indivíduo se relaciona com o meio e de como responde aos estímulos que ele oferece? Até que ponto a afirmação de Rousseau a melhor escola é a sombra de uma árvore pode ser levada em consideração? Alguns elementos como o calor, luz, vento, poeira e outros estímulos dificultam a concentração e, diante das distrações, o professor não deve forçar o ensino da leitura e da escrita, mas sim aproveitar aquele momento de relação com o meio (quando a borboleta passa, a folha da árvore voa sobre o caderno, etc.).

Outro aspecto consiste que as escolas ao ar livre não pressupõem um período permanente de exposição, ou seja, necessita algumas atividades internas, de reflexão, algum tipo de proteção para as situações naturais mais extremas, como a chuva, mas mantendo a maior parte dos espaços abertos. Como exemplo, aponta que os alunos podem estar a sombra de uma árvore, mas devem ter um refúgio próximo. Diante das belas experiências da natureza vem a questão principal: por que aprender regras gramaticais, contas de matemática? Como conclusões, a autora salienta que se tem seguido os programas previamente estabelecidos na instituição citada, como direções gerais e que os horários têm sido alterados sempre que o estado psicológico das meninas tem solicitado. Nesse sentido, destaca que as escolas ao ar livre estão inclinadas mais para a formação espiritual do que para uma soma de instrução predeterminada, dentro dos princípios da educação nova que pressupõe a natureza da criança, sua felicidade, que é uma acumulação de forças que estão para vir (Revista de Pedagogía, n. 85, 1929, p.15-22).

\footnotetext{
${ }_{11}^{11}$ Para um aprofundamento sobre a temática ver Châtelet et al (2003).

12 Educadora espanhola (1873-1961) que esteve envolvida com a escola pública, especialmente nas primeiras décadas do século 20. Foi diretora da Escola Bosque de Barcelona. 
Em uma abordagem mais ampla sobre a escola e o meio ambiente, Lourenzo Luzuriaga aborda os problemas trazidos por uma concepção pedagógica intelectualista e individualista do século 19 e a concepção social de princípios do século $20^{13}$. Neste sentido, o autor apresenta algumas ideias sobre um dos fatores da educação: o social ou externo, denominado sinteticamente de ambiente, ou seja, o contorno, circunstância ou mundo, algo que não podemos eleger, apenas nos é dado. Este constitui um dos elementos fundamentais da vida humana, segundo as ideias propostas por Ortega y Gasset. Assinala que devemos compreender por ambiente não apenas o meio imediato do homem, como a casa, os vizinhos, o povoado, etc., mas também as influências mais distantes, como leituras extraescolares, viagens, o conhecimento do pensamento de um homem extraordinário, situações que podem contribuir muito mais que algo cotidiano ou ordinário. Não se trata, nesse sentido, de compreender apenas o ambiente geográfico, mas também a importância do psicológico para entender a correlação entre homem e ambiente, considerando que o homem não apenas se adapta a este, mas age ativamente frente ao meio. Em relação à criança destaca que quanto menor a idade, maior é a influência do meio físico e biológico, sendo que na vida adulta a influência maior consiste do meio sociológico e histórico. Ainda em relação a criança podemos refletir sobre as interferências do ambiente extraescolar, como a família, os amigos, as leituras extraescolares, o cinema, as viagens, o bairro, a rua, entre outros e, o escolar, como o professor, o edifício, o espaço de jogos, a escola pública ou privada, as tradições, etc.

Para finalizar, o autor salienta que o tempo que a criança passa dentro do ambiente escolar em relação aos anos de vida é infinitamente pequeno, sendo assim, o ambiente extraescolar influencia muito mais na sua vida. Em contraponto, a escola por ter sua estrutura organizada, intensifica nesses poucos anos de estudo a influência sobre a vida da criança. Uma alternativa apontada para mudar essa situação é o aumento da escolaridade primária, até quatorze anos, e facilitar o acesso ao ensino médio e superior. Outras alternativas seriam o aumento do número de horas diárias na escola e a utilização do tempo de férias para atividades como colônias, campings e excursões. Outra opção seria aproximar a casa da escola, de um lado trazendo os pais e familiares para atividades e reuniões dentro do ambiente escolar e, por outro, fazendo com que o professor se aproxime das casas dos alunos pelas visitas, dando conselhos e informando sobre a situação dos alunos (Revista de Pedagogía, n. 138, 1933, p. 241-245).

Podemos visualizar que a escola ao ar livre, apesar de estar presente no discurso internacional, passou por uma tentativa de organização, tanto na Espanha, quanto em outros países europeus. A revista enfatiza a necessidade de conceituar, buscando esclarecer em meio aos profissionais de ensino as diferenciações entre uma escola ao ar livre, uma aula arejada e o preventoriums. Do ponto de vista do ambiente Luzuriaga

${ }^{13} \mathrm{O}$ autor destaca que a princípios do século 20 a concepção de homem e educação individualista é alterada pelas teorias de que consideram o homem um ser social: Nartop e Dewey. Essas ideias foram renovadas por Krieck, que considera a educação como uma das funções essenciais da sociedade e da história, como a arte ou a religião. Essas interpretações sociais da educação, assim como as concepções essencialmente individualistas, não apresentam explicações satisfatórias sobre o tema, segundo o autor. Para tanto, busca um equilíbrio entre ambos fatores, individual e social, com a nova filosofa fenomenológica e existencial - Husserl, Scheler, Heidegger - que são representadas no contexto espanhol sob a nova concepção filosófica da razão vital por Ortega y Gasset.

\begin{tabular}{|l|l|l|l|l|l|}
\hline Hist. Educ. (Online) & Porto Alegre & v. 21 & n. 51 & Jan./abr., 2017 & p. 297-316
\end{tabular}


apresenta discussões filosóficas e os diferentes meios que o homem convive ao longo da sua existência: biológico, físico e sociológico, enfatizando as influências do meio escolar e extraescolar e trazendo alternativas para que o ambiente escolar tenha uma ação mais educativa.

\section{Edifícios e construções escolares}

Em relação aos edifícios escolares o periódico reporta ao acordo feito pelo Instituto de Previsón a fim de destinar uma parte de sua arrecadação para o fomento de escolas públicas, visando a acelerar a construção dos edifícios escolares com os empréstimos ${ }^{14}$. Ainda, critica a discrepância entre províncias dotadas de um número significativo de escolas - Centro, Norte e Noroeste - em contraponto ao Sul, especialmente Andaluzia, com a falta de auxílios para construções escolares (La construcción de edifícios para escuelas, Revista de Pedagogía, n. 29, 1924, p.188-189).

Realizando um levantamento acerca dos edifícios escolares da Espanha apresenta uma nova publicação da seção de Informaciones, publicaciones y estatísticas del Ministerio de Instrucción Pública (1926), sobre a situação dos prédios escolares. Esse material não apenas classifica as construções como bom, regular ou mal, mas incorpora as principais características e os classificam a partir dessas. Descreve questões de propriedade: os municípios possuem o maior número de edifícios, muitos alugados, já que está a seu cargo os prover; data de construção dos edifícios, casa do professor; superfície e orientação das salas (Los edificios escolares de España, Revista de Pedagogía, n. 58, 1926).

Ainda sobre as construções escolares na Espanha salienta a existência de uma exaltação para a necessidade da construção de edifícios, que deve ser realizado em conjunto com a melhora das condições daqueles que existentes, que passam por situações muito complicadas desde o ponto de vista higiênico ${ }^{15}$. Outra questão primordial consiste na divisão equitativa para todos os povoados da Espanha, excluindo das construções tudo o que for supérfluo e represente um luxo, buscando o barateamento das construções. Um exemplo lamentável, segundo o periódico, são os recém-inaugurados grupos escolares de Madrid, com edifícios presunçosos e ostensivos, mas sem espaço suficiente para os alunos desenvolverem suas atividades. Reforçam a ideia de que os edifícios escolares deveriam basear-se em escolas baratas e em meio natural, edificação simples, grandes janelas, serviços higiênicos amplamente atendidos, campos de jogos e, se possível, bosques e vegetação circundante. Esse movimento, em torno de uma escola simples, higiênica e econômica, deveria ser posto em pauta primeiramente pelo próprio Ministério, assinalando em sua pauta essas condições, pois assim se poderia construir o dobro de escolas que se tem hoje (Revista de Pedagogía, n. 92, 1929, p. 374-376).

Propondo uma discussão em relação aos edifícios escolares Juan Llarena aponta que a primeira questão que merece destaque é a necessidade crescente desse tipo de construção. Em seguida considera que o espaço não pode ser visto como um fetiche, ou seja, o papel do professor, do método, programa, exercício ou hábito são mais eficazes

\footnotetext{
${ }^{14}$ Para mais informações ver Fomento y construcción de escuelas Nacionales (Madrid, 1924), que acompanha uma série de tipos de edifícios escolares criados pela Oficina Tecnica del Ministerio de Instrucción Publica. Obra consultada na Biblioteca del Minsterio de Educación. Madrid/Espanha.

15 Para uma análise das instruções técnico-higiênicas sobre as construções escolares no período, ver Construcción de edifícios-escuelas, real decreto de 1928 (Madrid, 1928). Obra consultada na Biblioteca del Minsterio de Educación. Madrid/Espanha. Para um estudo mais amplo sobre higiene e arquitetura na Espanha, entre 1838 e 1936, ver Purificación (1992).

\begin{tabular}{|l|l|l} 
Hist. Educ. (Online) & Porto Alegre & v. 21
\end{tabular}

$\begin{array}{ll}\text { v. } 21 & \text { n. } 51\end{array}$

Jan./abr., 2017

p. $297-316$
} 
do que o local e o material. No entanto, o lugar jamais é desprezível ou indiferente, sendo que o espaço escolar deve proporcionar atividades de aula, jogos, trabalhos, chuveiros, banheiros, cantina, biblioteca, museu, festas, esportes, veladas, assembleias, ginasticas. No caso do Grupo Escolar Baixeras, Barcelona, é salientado que o pior é a casa, em meio ao barulho da rua, dos carros, sem ar puro, sem entrada de sol nas aulas, conforme ocorria também ocorre com diferentes grupos madrilenos. O segundo ponto é o barateamento da construção, outro é a rapidez, já que o Estado criava situações que provocam a demora de meses ou anos para se empreender uma construção (Revista de Pedagogía, n. 99, 1930, p. 129-131).

Trazendo mais uma vez o contexto espanhol Gervasio Manrique destaca primeiramente o estímulo - propaganda sobre as construções escolares, fazendo que com cada vila - por mais humilde que seja - tenha seu projeto para construir uma escola. Mesmo que as cidades pequenas ainda não tenham a escola ideal, considerada pelo autor uma "escola alegre e bela" (Revista de Pedagogía, n. 105, 1930, p. 402), o importante é cultivar a necessidade em que cada povoado se tenha uma escola. Destaca que nas principais cidades espanholas se tem inaugurado ou estão em construção os grupos escolares, mas deve-se harmonizar a situação no sentido de estimular financeiramente as cidades com menores recursos. Ainda, realiza uma crítica quanto aos modelos de edifícios escolares grandiosos, devendo acompanhar a arquitetura popular e as condições geográficas de cada região. Cita os exemplos bem-sucedidos dos municípios de Vizcaya e Soria, com construções adaptáveis à realidade do povoado. As escolas, assim como as igrejas que representam a religiosidade da época medieval, deveriam representar uma cultura espanhola desse tempo, o início do século 20. Para finalizar o autor indaga: seria conveniente construir a casa do professor junto com a escola? Como resposta, destaca que deve ser pensada e, especialmente, nos meios rurais, onde muitas vezes o professor não encontra facilmente uma casa para alojar-se, deve-se construir a casa do professor e a escola (Revista de Pedagogía, n. 105, 1930, p. 398-404).

Em relação à quantidade numérica de escolas, outro artigo aponta o recorde do governo com a criação de milhares de escolas de uma só vez. De forma sucinta relata que a República espanhola não apenas cria essas escolas, mas também melhora notavelmente o salário dos professores, fator que os estimulará a manter fidelidade à república. Com um discurso entusiasmado e otimista, em relação à construção de edifícios e ao salário dos professores, consideram esses elementos favoráveis ao desenvolvimento do atrasado sistema de ensino primário espanhol em comparação a outros países europeus (Revista de Pedagogía, n. 119, 1931, p. 520-521).

Ainda sob o ponto de vista quantitativo apresenta que a República espanhola anunciou a criação de 20.000 edifícios escolares, 13 mil a mais do que o ano anterior. Desse modo, mesmo diante da crise mundial, a Espanha passaria de uma nação com sérios problemas em seu sistema de ensino para a nação que mais investe em esta questão, pois havia sido aprovado pelo Parlamento o empréstimo de 400 milhões de pesetas para as construções escolares. O próximo passo deveria constituir uma comissão central e outras regionais e provinciais integradas por arquitetos, médicos, profissionais de ensino e representantes de organismos locais (Revista de Pedagogía, n. 129, 1932, p. 423). 
A partir de um olhar mais qualitativo outro artigo apresenta os debates em torno das construções escolares empreendidas pelo Ministério de Instrução Pública, destacando que diversos aspectos: político, econômico, arquitetônico, higiênico, pedagógico. Salienta que alguns críticos das construções escolares consideram que do empréstimo de 400 milhões de pesetas, 200 milhões deveriam ser encaminhados para substituir o ensino das ordens religiosas. Como resposta, o Ministério esclarece que a substituição das ordens religiosas deve ser resolvida de forma independente do empréstimo para construções escolares.

De acordo com a proposta do Ministério, além do problema político-econômico, o pedagógico deveria também ser abordado, argumentando que a escola, assim como a casa, necessitava ser funcional, como uma máquina. No entanto, como a função da escola é a educação e, a concepção contemporânea é a escola ativa e viva, enfatiza uma questão central: como refletir esse conceito de educação no edifício escolar? Como resposta, lista 8 pontos que deveriam ser seguidos: 1) substituir imensos edifícios por menores, facilitando o movimento das crianças; 2) criar um campo de jogos em todas as escolas urbanas e um campo agrícola em todas as escolas rurais; 3 ) instalar oficinas e bibliotecas em salas próprias, com serviços complementares (ducha, refeitório, cozinha); 4) deixar o maior espaço possível para o sol e a luz em aula e campo, seguindo a orientação sempre que possível ao meio dia (em oposição ao modelo tradicional setentrionalista); 5) suprimir a imobilidade do mobiliário escolar, que deve ser variável conforme as necessidades do ensino; 6) não criar tipos rígidos e uniformes de escolas, mas sim adequados aos tipos locais e regionais da Espanha; 7) estruturar todos os edifícios às normas de simplicidade, suprimindo os ornamentos que são anti-higiênicos e antiestéticos; 8) não considerar a sala de aula e o edifício escolar como único e decisivo na educação, mas realizar em excursões, colônias, etc., levando a escola à vida (Revista de Pedagogía, n. 134, 1933, p. 88-89).

Reforçando a ideia dos gastos com os edifícios como um dos principais problemas, considera um absurdo o que vem sendo investido na Espanha - como também o exemplo da França - na construção de grupos escolares grandiosos, que são erguidos sob o comando de comissões que ignoram as necessidades da infância e dos novos métodos educativos. Salienta que as janelas, por exemplo, não possuem o tamanho adequando para entrada de ar e luz; os móveis, fixos e pesados, não permitem o movimento necessário nas salas de aulas e, ainda, não destinam espaços para elaboração da horta e jardim escolar. Os arquitetos deveriam compreender que os edifícios escolares são destinados às crianças e que os métodos educativos são variáveis. Para tanto, deve-se evitar altos custos, móveis fixos, com espaços destinados às oficinas de desenho, carpintaria, biblioteca, laboratórios científicos, teatro, ginásio, etc, que possam ser facilmente adaptáveis a outras necessidades da educação (Revista de Pedagogía, n. 138, 1933, p. 270).

Se distanciando um pouco do viés da construção, temos a menção em relação às dificuldades que a Espanha enfrenta para manter a limpeza e reparos necessários dos grandes grupos escolares construídos nos últimos anos, especialmente com a umidade e, por consequência, a manutenção do sistema de calefação. O tema central consiste na indagação: depois das construções finalizadas, quem irá mantê-las? Para tanto, salienta que o professor não tem condições de limpar, pois os edifícios possuem estruturas 
monumentais, sendo os gastos, como por exemplo de um Grupo Escolar de Madrid, chega a mais de 4.000 pesetas anuais. Diante dessa situação, questiona: quem deve ser responsável pela manutenção dos edifícios escolares? Estado, município ou ambos? 0 artigo manifesta um tom de denúncia da situação em que se encontram os edifícios escolares pela Espanha, buscando responsáveis para amenizar essa situação (Revista de Pedagogía, n. 143, 1933, p. 522-524).

Analisando um tema mais específico o arquiteto Manuel Vías Sáenz-Díez relata que existe na Espanha sérios problemas quanto à arquitetura escolar, em termos quantitativos e qualitativos. Destaca que o meio rural é o mais desprovido de edifícios e tanto legisladores quanto arquitetos desconhecem essa realidade, devendo o Estado empreender esforços para multiplicar as chamadas escolas mínimas: uma aula de assistência mista ou duas classes em localidades pequenas ou lugares afastados ${ }^{16}$. Os dois principais problemas nessa situação são: a falta de conhecimentos técnicos de arquitetos para esse tipo de construção e falta de mão-de-obra nas áreas rurais. Algumas recomendações são colocadas aos arquitetos: em caso de uma escola acolher crianças de diferentes povoados e estas necessitam fazer suas refeições na escola, seria imprescindível a presença de refeitório e cozinha, mesmo sendo o mais simples possível. No caso das crianças que vivem em casas próximas, a mesma não deve possuir esses espaços. Em relação à biblioteca, no caso de a escola receber alunos de outros povoados, a biblioteca deve ser ambulante, para se deslocar por diferentes regiões. Os edifícios dos meios rurais devem possuir a moradia do professor, já no caso dos sanitários e serviços de calefação, necessitam ser estudados sobre sua necessidade. Quanto à escolha do terreno prescreve-se observar especialmente sua localização, orientação solar, vento e fácil acesso em relação às casas. Propõe-se dar prioridade para o uso de materiais existentes na região, os elementos fundamentais da sala de aula devem ser: janela, porta, piso, rodapés, quadro negro e armários.

Logo após realizar essas recomendações, apresenta um quadro com alguns exemplos de construções escolares mínimas em pequenos povoados, como Navahondilla (Ávila); Villamoñico (Santander); Zarzalejo e El Escoreal (Madrid); Cillamayor (Palência); Torremenga (Cárceres). Para finalizar aponta que: "com voluntad y um mínimo de sacrifício las nuevas escuelas pueden llegar hasta el ultimo rincón de España". O artigo acompanha fotografias dos edifícios de Torremenga (Cárceres); Zarzalejo e El Escoreal (Madrid) (Revista de Pedagogía, n. 145, 1934, p. 27).

De autoria do mesmo arquiteto, Manuel Vías, há uma série de questões do decreto de 15 de junho de 1934, referente às construções escolares. Destaca os problemas que os municípios passam ao terem que cumprir uma grande burocracia em um curto espaço de tempo, a fim de conseguir autorização e empréstimo para as construções. Salienta alguns acertos do decreto, como no artigo 17, que eleva o valor de 3.000 pesetas para o município que construir junto a escola a casa do professor; o artigo 21 que determina que os serviços sanitários apenas poderão ser instalados em escolas que possuírem água corrente a pressão, tendo em vista que as instalações que não possuem essas condições constituem um gasto perdido e focos de infecção. Nos artigos 6 e 16 salienta que escolha do terreno feita pelo arquiteto que deve visitar o povoado e não pelo professor; o artigo

\footnotetext{
${ }^{16}$ Para aprofundar a investigação acerca da arquitetura escolar rural, ensino, organização, construção e instalação, com inúmeros planos, plantas e projetos, ver Martí Alpera (1934). 
21 estabelece que a Oficina Técnica tem o prazo de 30 dias para simplificar as orientações técnicos-higiênicas. Ainda, aponta a redução do limite de altura das salas de aulas, que além de economizar durante a construção, também diminuem os gastos com calefação.

Outras breves observações relativas ao decreto, como os artigos 2 e 27, sobre o reembolso dos valores empregados pelos municípios, que são muito teóricos, o número de exceções, reservas e condições que serviriam de justificativa a todo gênero de injustiças e preferencias. Para finalizar, relata que o decreto apresenta acertos, mas alguns artigos são essencialmente teóricos e outros um tanto perturbadores. $O$ arquiteto é otimista, destacando que apesar da lentidão e burocracia que envolvem especialmente as construções dos pequenos povoados, espera que esse processo seja simplificado (Revista de Pedagogía, n. 152, 1934).

Em relação aos edifícios e construções escolares, observamos que a maioria dos artigos são provenientes do setor de Informaciones e Notas del mes da Revista de Pedagogía. Apresentam, basicamente, um levantamento em torno da necessidade da construção de edifícios escolares, discutindo a relação entre a quantidade e a qualidade, sendo unânime a posição do periódico que as escolas devem ser construídas de forma econômica, sem monumentalidade, ornamentos e acessórios que tenham como fim o caráter decorativo. Outro aspecto de crítica constante são os trâmites que o Estado estabelece para a concessão de empréstimos aos municípios e o tempo gasto nas construções. A presença discursiva em defesa da escola pública em todas as regiões da Espanha, sendo que as construções devem acompanhar a realidade de cada povoado. A concepção da arquitetura escolar como fator educativo está presente na prescrição de espaços, assim como na necessidade de adaptação do edifício aos novos métodos de ensino e a realidade geográfica, social, cultural, econômica de cada região.

\section{Mobiliário e material escolar}

Sobre o material escolar temos considerações acerca da necessidade destes para o bom funcionamento da escola e a defesa de sua gratuidade, já que sem ele não era considerado possível um bom processo de instrução. Também, entende o material como um meio, não devendo atribuir-lhe a missão de uma boa escola, como por exemplo, no caso das escolas privadas onde os materiais são abundantes, mas nem sempre utilizados (Revista de Pedagogía, n. 29, 1924, p.188-189).

Em relação às principais concepções da escola nova Gertrudis Hartman analisa a influência dos estudos de Psicologia para o desenvolvimento da criança, por meio da atividade $^{17}$. Visando facilitar essa atividade a escola deveria ter um ambiente favorável, com espaço suficiente e materiais móveis para que as crianças possam manejá-los com facilidade, sob os princípios de sua personalidade ou originalidade. Outro aspecto importante seria de compreender a criança como um ser social que necessita estar e falar

\footnotetext{
${ }^{17}$ Para uma análise interessante sobre a incidência da Junta para Ampliación de Estudios, na modernização da escola espanhola e a inovação do material escolar através dos manuais de pedagogia (1875-1936), ver Romero; Ramos; Ruiz Berrio (2007). Hist. Educ. (Online) $\quad$ Porto Alegre v. 21 ก. 51 Jan./abr., 2017 p. $297-316$
} 
livremente com o grupo, respeitando os aspectos e desejos coletivos, assim como as necessidades individuais. Recomenda programas flexíveis, projetos de investigação a partir dos interesses dos alunos, com um trabalho mais criativo do que imposto (Revista de Pedagogía, n. 46,1925, p. 468).

Nas questões referentes ao material de ensino é citato um estudo de Artur Dumke, publicado na revista alemã Neue Bahenen sobre as três direções da reforma do ensino: primeiro, o propósito de partir da vida da criança, levar sua realidade a escola; segundo, a necessidade de exercitar determinadas destrezas e esferas do saber; terceiro, o ensaio de dar um ensino especializado. De acordo com o periódico, o problema do ensino na Espanha consistia na acertada síntese dessas três possibilidades. A partir dessa introdução coloca o questionamento: que significado tem isso para o material docente? A primeira direção parece mais evidente, ou seja, que a criança fale de sua realidade, de seu ambiente, um objeto sensível. Tal objeto pode ser para o ensino do ambiente, assim como para o ensino da natureza, com elementos de significado geográfico, histórico, literário. O material docente facilita assim a entrada na escola da realidade sensível da criança.

Em relação ao material especial salienta que está inteiramente entregue aos cuidados e a inteligência do professor, sendo que a prática poderá ser realizada facilmente, sobretudo, na educação básica. Destaca que existe há muito tempo esse tipo de materialidade na escola, mas que se converteu em mais um material de demonstração, com exceção especial da Física, porque a mesma constitui uma ciência natural generalizadora. Após essa análise das condições específicas dessa disciplina constata que existe uma evidente graduação de possibilidades de representar um objeto espiritual. A partir de então apresenta uma série de possibilidades de materialidade para estudo na Geografia e História, que além dos mapas e globos, devem ser utilizados topogramas, imagens e sons, projeções e, se possível, o cinematógrafo. Para finalizar, aponta a importância do trabalho manual, que além de satisfazer as crianças, obriga um trabalho de cooperação, ação e expressão, dando vida ao ensino (Revista de Pedagogía, n. 131, 1932, p. 514).

Estabelecendo uma discussão entre a realidade nacional espanhola e as experiências de outros países, comenta acerca da aquisição de mesas-banco para as escolas nacionais espanholas, destacando o progresso nos processos pedagógicos administrativos, assim como a necessidade de ampliar para todos os aspectos da materialidade escolar. Como exemplo, menciona o caso da mesa-banco com um modelo único do Museu Pedagógico Nacional, que é de reconhecida qualidade não só da Espanha, mas também em comparação a outros países. No entanto, o artigo aponta que seria conveniente ampliar as possibilidades a partir de concursos para outros modelos, pois de acordo com as concepções pedagógicas, a escola não deveria ter um caráter artificial e, retirar do seu espaço toda a materialidade que o assim fizesse para transformar-se em um modelo elevado da casa da criança. Uma recomendação seria o modelo Montesorri, de mesas-banco, mesas e cadeiras que se possam mover, mesas planas, que rompem com a simetria excessiva. Esse modelo seria de mais fácil aquisição e barato, que algumas escolas já faziam uso e que devem ser incorporadas também pelo Estado, além do modelo do Museu Nacional (Revista de Pedagogía, n. 35, 1924, p. 425426). 
Outro exemplo internacional consiste no modelo de mobiliário móvel da cidade de Cleveland, Estados Unidos, que equipou suas escolas com o novo modelo movible: mesas e bancos não fixos. Apresentando posições a favor ou contra, suscita pontos não favoráveis, pois estimula muitas conversas entre os alunos, conformidade na forma de pensar e perda da individualidade. Por outro, destaca que apenas as prisões e as escolas estabelecem lugares fixos para as pessoas, como uma cela ou um banco, tendo em vista que a escola tradicional trata um grupo de 40 alunos dentro de uma perspectiva de homogeneidade. Como alternativa de equilíbrio entre as opiniões, salienta que os grupos menores são mais eficazes para trabalhar e reconhecer as diferenças individuais. Os cochichos entre os alunos são considerados necessários para o desenvolvimento do processo educativo e os pequenos grupos para discussões livres, preparação para as novas complexidades e situações vitais do ser humano (Revista de Pedagogía, n. 99, 1930, p. 129-131).

Em relação ao material e mobiliário escolar é recorrente o estímulo às prerrogativas da Escola Nova, como a utilização de objetos em sala de aula, a fabricação própria e seu livre manuseio pelos alunos, a incorporação de artefatos que façam parte da realidade e do seu entorno, como da família, povoado, bairro, etc. A recomendação quanto ao mobiliário é a flexibilidade e adaptação, assim como a ampliação de modelos e a livre escolha por parte da instituição daquilo que seria o mais adequando para a sua realidade. Reconhece as dificuldades que, muitas vezes, os professores enfrentam ao trabalharem em um ambiente menos tradicional, mas defende uma educação mais humana, que discuti problemas, conhece o meio ambiente e estabelece relações entre os indivíduos.

\section{Considerações finais}

Constatamos que o discurso presente na Revista de Pedagogía em torno dos espaços, edifícios, mobiliário e material escolar estava alinhado às tendências internacionais sobre a necessidade de prédios construídos especialmente para escolas e o mobiliário cada vez adaptado à localidade, clima, geografia, dentre outras questões físicas, sociais, culturais e econômicas. O espaço escolar não era compreendido como o elemento mais importante, mas sim como um meio educativo, que deveria estar alinhado a outros, como o trabalho dos professores, métodos e programas de ensino.

O número elevado de artigos que abordam o tema arquitetura escolar corresponde ao significativo empreendimento financeiro na construção de edifícios para escolas primárias, os levantamentos estatísticos, modelos e projetos. Seguem os padrões internacionais quanto aos cuidados médico-higiênicos e os pressupostos da Escola Nova: instalação de sanitários, laboratórios de ensino, museus, biblioteca, refeitório, sala de jogos, espaço para prática de esportes, etc. O mobiliário e material escolar deveriam proporcionar condições para criar, manusear, experimentar, relacionar, tanto com os objetos como o mobiliário. Quanto mais adaptável e flexível melhor para desenvolver os processos de aprendizagem.

Desse modo, os artigos analisados constituem um panorama de como um periódico pedagógico científico, fundado e dirigido por um dos mais conhecidos pedagogos espanhóis do início do século 20, apresenta e discute um dos temas mais recorrentes 
no período, os espaços e a materialidade escolar. De uma necessidade de expansão da escola primária pública, com os edifícios e materiais adequados para o funcionamento das aulas, temos uma mostra importante da presença discursiva de especialistas tanto no campo educativo, como arquitetônico.

\section{Referências}

BALTAR, Francisca Maria Teresa dos Reis. Arquitetura de escolas no século 19: orimeiras escolas construídas no Brasil. Hist. Educ. (Online), Porto Alegre: Asphe, v. 5, n. 10, 2001, p. 53-84.

BARREIRO, Herminio. Lorenzo Luzuriaga y el movimiento de la escuela unica en España. De la renovación educativa al exilio (1913-1959). Revista de Educación, n. 289, 1989, p. 7-48.

BASTOS, Maria Helena Camara. A educação como espetáculo. In: STEPHANOU, Maria; BASTOS, Maria Helena. Histórias e memórias no Brasil. v. Il século 19. Petrópolis: Vozes, 2005, p.116-131.

BASTOS, Maria Helena Camara. Imprensa e cultura escolar: percursos da pesquisa sobre imprensa estudantil no Brasil. In: HERNÁNDEZ DÍAZ, José Maria (org.). II Jornadas de prensa pedagógica: la prensa de los escolares y estudiantes. Salamanca: Salamanca, 2015, p. 21-43.

BENCOSTTA, Marcus Levy Albino (org.). História da educação, arquitetura e espaço escolar. São Paulo: Cortez, 2005.

BENCOSTTA, Marcus Levy Albino. Arquitetura e espaço escolar: o exemplo dos primeiros grupos escolares de Curitiba (1903-1928). In: BENCOSTTA, Marcus Levy Albino (org.). História da educação, arquitetura e espaço escolar. São Paulo: Cortez, 2005, p.141-170.

BENCOSTTA, Marcus Levy Albino. Desafios da arquitetura escolar: construção de uma temática em história da educação. In: OLIVEIRA, Marcus Aurélio Taborda de (org.). Cinco estudos em história da educação. Belo Horizonte: Autêntica, 2007, p. 111-125.

BRASTER, Sjaak; GROSVENOR, lan; POZO, María del Mar (eds.). The black box of schooling: a cultural history of the classroom. Brussels: Peter Lang, 2011.

BUFFA, Ester; PINTO, Gelson de Almeida. Arquitetura e educação: organização do espaço e propostas pedagógicas dos grupos escolares paulistas, 1893-1971. São Carlos: Brasília: UFSCar/Inep, 2002.

BURKE, Catherine; GROSVENOR, lan (org.). School. London: Reaktion Books, 2008.

CHÂTELET, Anne Marie; Lerch, Dominique; Luc, Jean-Noël (direc.). L'école de plein air: une expérience pédagogique et architecturale dans I'Europe du XX siècle. Paris: $E$. Recherches, 2003.

CHÂTELET, Anne-Marie. Ensaio de historiografia I: a arquitetura das escolas no século XX. Hist. Educ. (Online), Porto Alegre: Asphe, n. 20, 2006, p. 7-38.

CHÂTELET, Anne-Marie. La naissance de l'architecture scolaire: les écoles élémentaires parisiennes de 1870 à 1914. Paris: Honoré Champion, 1999.

CLASES AIREADAS, ESCUELAS AL AIRE LIBRE PREVENTORIUMS. Revista de Pedagogía, Informaciones, n. 12, 1922, p. 470-472.

CUATROCIENTOS MILLONES PARA EDIFICIOS ESCOLARES. Revista de Pedagogía, Notas del mes, n. 129, 1932, p. 423. 
EL MATERIAL DE ENSEÑANZA. Revista de Pedagogía, Informaciones, n. 131, 1932, p. 514-517.

EL MATERIAL ESCOLAR. Revista de Pedagogía, Notas del mes, n. 29, 1924, p. 187-188.

EL MOBILIARIO ESCOLAR MOVIBLE EN LOS ESTADOS UNIDOS. Revista de Pedagogía, n. 99, 1930, p. 129-131.

EL MOBILIARIO PEDAGÓGICO. Revista de Pedagogía, Notas del mes, n. 35, 1924, p. 425-426.

EL PROBLEMA DEL ENTRETENIMIENTO DE LOS EDIFICIOS ESCOLARES. Revista de Pedagogía, Notas del mes, n. 143, 1933, p. 522-524

ESCOLANO, Agustín Benito. Arquitetura como programa: espaço-escola e currículo. In: VIÑAO, Antonio; ESCOLANO, Agustín. Currículo, espaço e subjetividade: a arquitetura como programa. Rio de Janeiro: DP\&A, 1998, p. 19-57.

ESCOLANO, Agustín Benito. La arquitetura como programa: espacio-escuela y curriculum. Revista Historia de la Educación, n. 12-13, 1993-94, p. 97-120.

ESCOLANO, Agustín Benito. Tiempos y espacios para la escuela: ensaios historicos. Biblioteca Nueva. Madrid, 2000.

FARIA FILHO, Luciano M. Dos pardieiros aos palácios: cultura escolar e urbana em Belo Horizonte na Primeira República. 1 ed. Passo Fundo: UPF, 2000.

FARIA FILHO, Luciano M. Dos pardieiros aos palácios: forma e cultura escolar em Belo Horizonte (1906/1918). 2 ed. Uberlândia: UFU, 2015.

FARIA FILHO, Luciano Mendes; VIDAL, Diana Gonçalves. Os tempos e os espaços no processo de institucionalização da escola primária no Brasil. Revista Brasileira de Educação, n. 14, 2000, p. 19-34.

FELGUEIRAS, Margarida Louro. A arquitectura da escola primária em Portugal nos séculos 19 e XX. In: FERNÁNDEZ, Juan Gómez; TOCINO, Gloria Espigado; MIRANDA, Miguel Beas (eds.). La escuela y sus escenarios: actas de los IX Encuentros de Primavera en El Puerto. El Puerto de Santa María: Concejalia de Cultura e Ayuntamiento de El Puerto de Santa María, 2007, p. 37-65.

FELGUEIRAS, Margarida Louro. Cenografias de escolarização: os edifícios escolares da ditadura. Contributos, n. 6, 2006, 153-172.

FELGUEIRAS, Margarida Louro. O significado das escolas Conde de Ferreira na instrução pública em Portugal. In: Felgueiras, Margarida Louro; Graça, Odete (coord.). Escolas Conde de Ferreira: marco histórico da instrução pública em Portugal. Sesimbra: Assembleia Municipal, 2009, p. 29-38.

FELGUEIRAS, Margarida Louro. Schools buildings as a context to understand our common past. In: FELGUEIRAS, Margarida Louro; FERREIRA, António Gomes (eds.). Buildings telling european heritage. Coimbra: Centro de Estudos Interdisciplinares do Século XX, 2008, p. 157-162.

FOSSATI, Pietro. L'edilizia per le scuole del popolo nell'Ottocento genovese. History of Education \& Children's Literature, v. IX, n. 2, 2014, p. 445-466.

HERNÁNDEZ DIAZ, José Maria (dir.). Prensa pedagógica em Castilla y Léon (17931936): repertorio analítico. Salamanca: Hergar Ediciones Antema, 2013b. 
HERNÁNDEZ DIAZ, José Maria. Prensa pedagógica y património educativo em España: conceptualización y géneros textuales. In: HERNÁNDEZ DÍAZ, José Maria (ed.). Prensa pedagógica y património histórico educativo. Salamanca: Universidad de Salamanca, 2013a, p. 15-32.

KUHLMANN JR., Moysés. As grandes festas didáticas: a educação brasileira e as exposições internacionais 1862-1922. Bragança Paulista: USF, 2001.

LA CONSTRUCCIÓN DE EDIFICIOS PARA ESCUELAS. Revista de Pedagogía, Notas del mes, n. 29, 1924, p.188-189.

LA CREACIÓN DE 7000 ESCUELAS. Revista de Pedagogía, Notas del mes, n. 119, 1931, p. 520-521.

LANERA, Juan. Construcciones escolares. Revista de Pedagogía, n. 99, 1930, p. 112115.

LAS CONSTRUCCIONES ESCOLARES. Revista de Pedagogía, Notas del mes, n. 92, 1929, p. 374-376.

LAS CONSTRUCCIONES ESCOLARES. Revista de Pedagogía, Notas del mes, n. 134, 1933, p. 88-89.

LÓPEZ, Martínez; DELGADO, Martínez. La enseñanza de las ciencias escolares en la Revista de Pedagogía (1922-1936). In: Revista Educació i Història, n. 24, 2014, p. 69-101. Disponível em <http://revistes.iec.cat/index.php/EduH/article/view/95960/95587>. Acesso em 15 maio 2016.

LOS EDIFICIOS ESCOLARES COMO FACTOR EDUCATIVO. Revista de Pedagogía, Informaciones, n. 138, 1933, p. 269-271.

LOS EDIFICIOS ESCOLARES DE ESPAÑA. Revista de Pedagogía, Informaciones, n. 58, 1926, p. 462-464.

LUZIRIAGA, Lourenzo. La escuela y el medio ambiente. Revista de Pedagogía, n. 138, 1933, p. 241-245.

MADRID. Construcción de edificios-escuelas, Real Decreto de 1928: instrucciones técnico-higiénicas. Modelo de documentos administrativos. Madrid: Tipografia Yagues, 1928.

MADRID. Estadísticas de edificios-escuelas. Escuelas Nacionales: condiciones de los edificios, condiciones de las clases. Madrid: Imprenta de Sordomudos y de Ciegos, 1926.

MADRID. Fomento de construcción de escuelas nacionales: Instituto Nacional de Previsión. Instrucciones para la tramitación y Concesión de préstamos a los ayuntamientos. Madrid: Oficina Graficas Reunidas, 1924.

MANRIQUE, Gervasio. Las construcciones escolares en España. Revista de Pedagogía, n. 105, 1930, p. 398-404.

MARTÍ ALPERA, Felix. Las escuelas rurales: enseñanzas, organización, construcción, instalación. Madrid-Gerona: Dalmau Carles, 1934.

MATASCI, Damiano. L'École republicaine et l'etranger: une historie internationale des reformes scolaires em France. 1870-1914. Lyon: ENS, 2015.

MATERIALES Y MÉTODOS DE LA NUEVA EDUCACIÓN. Revista de Pedagogía, Informaciones, n. 46, 1925, p. 468-469

MÉRIDA NICOLICH, Eloísa. Indice de la Revista de Pedagogía (1922-1936). Pamplona: Eunsa, 1983b. 
MÉRIDA NICOLICH, Eloísa. Una alternativa de renovación pedagógica: la Revista de Pedagogía (1922-1936). Pamplona: Eunsa, 1983a.

MOTILLA, Xavier Salas; GONZÁLEZ, Sara Gómez. La utilización del grabado en El Buen Amigo: periódico para la enseñanza de niños y adultos de Joan Benejam Vives. In: PADRÓS, Núria et al. COLOQUIO DE HISTORIA DE LA EDUCACIÓN, 18, 2015. Actas ... Barcelona: Universitat de Vic-Barcelona, 2015, p. 409-423.

PESAVENTO, Sandra Jathay. Exposições universais: espetáculos da modernidade do século 19. São Paulo: Hucitec, 1997.

PURIFICACIÓN, Lahoz Abad. Higiene e arquitectura escolar en la España contemporánea (1838-1946). Revista de Educación, n. 298, 1992, p. 89-118.

RODRIGUEZ MENDÉZ, Francisco Javier. Arquitectura escolar en España (1857-1936): Madrid como paradigma. Madrid: Escuela Técnica Superior de Arquitectura, 2004. 1174f. Tese (doutorado em Arquitetura). Escuela Técnica Superior de Arquitectura de Madrid.

RODRIGUEZ MENDÉZ, Francisco Javier. La institución de libre enseñanza y la arquitectura escolar. Historia de la Educación, Universidad de Salamanca, n. 25, 2007, p. 467-491.

ROMERO, Teresa; RAMOS, Sara; RUIZ, Julio. Incidencia de la Junta para la Ampliación de Estudios en la modernización de la escuela española: la innovación del material escolar a través de los manuales de Pedagogía, 1875-1936. In: ESCOLANO, Agustín Benito (ed.). La cultura material de la escuela: en el centenario de la Junta para la Ampliación de Estudios 1907-2007. Salamanca: Varona, 2007, p. 131-154.

SENSAT, Rosa. La escuela al aire libre. Revista de Pedagogía, n. 85, 1929, p. 15-22.

SILVA, Carlos Manique da. A ideia de casa de escola no século 19 português. Revista da Faculdade de Letras - História, v. 6, 2005, p. 291-312.

SILVA, Carlos Manique da. A organização do espaço nas primeiras escolas graduadas (décadas de 1870-1880). In: Felgueiras, Margarida Louro; Graça, Odete (coord.). Escolas Conde de Ferreira: marco histórico da instrução pública em Portugal. Sesimbra: Assembleia Municipal, 2009, p. 87-96.

SILVA, Carlos Manique da. Escolas belas ou espaços sãos? Uma análise histórica sobre arquitetura escolar portuguesa (1860-1920). Lisboa: Instituto de Inovação Educacional, Lisboa, 2002.

SILVA, Carlos Manique da. O estudo dos espaços escolares: balanço da investigação científica portuguesa (2005-2014). In: ALVES, Luis Alberto Marques; PINTASSILGO, Joaquim. História da educação fundamentos teóricos e metodologias de pesquisa: balanço da investigação portuguesa (2004-2015). Porto: Centro de Investigação Transdisciplinar, Cultura Espaço e Memória, 2015, p. 131-147,

TRILLA, Jaume. Ensayos sobre la escuela: el espacio social y material de la escuela. Barcelona: Laertes, 1999.

VÍAS SÁENZ-DIEZ, Manuel. La arquitectura rural escolar. Revista de Pedagogía, n. 145, 1934, p. 21-27.

VÍAS SÁENZ-DIEZ, Manuel. Las construcciones escolares. Revista de Pedagogía, n. 152, 1934, p. 358-362.

VIÑAO, Antonio. Do espaço escolar e da escola como lugar: propostas e questões. In: Viñao, Antonio; Agustín Escolano. Currículo, espaço subjetividade: a arquitetura como programa. Rio de Janeiro: DP\&A, 1998, p. 59-139. 
VIÑAO, Antonio. El espacio escolar: introducción. Revista Historia de la Educación, n. 1213, 1993-94, p. 11-16.

VIÑAO, Antonio. Espacio y tiempo: educación y historia. Morelia: Imced, 1996.

VIÑAO, Antonio. Espaços, usos e funções: a localização e disposição física da direção escolar na escola graduada. In: BENCOSTTA, Marcus Levy Albino (org.). História da educação, arquitetura e espaço escolar. São Paulo: Cortez, 2005, p. 15-47.

VIÑAO, Antonio. Sistemas educativos, culturas escolares y reformas: razones y propuestas educativas. Madrid: Morata, 2002.

VIÑAO, Antonio; Escolano, Agustín. Currículo, espaço e subjetividade: a arquitetura como programa. Rio de Janeiro: DP\&A, 1998.

WARDE, M. J. Oscar Thompson na Exposição de St. Louis (1904): a exhibit showing machinery for making machines. In: FREITAS, Marcos Cezar de; KUHLMANN JR., Moysés (orgs.). Os intelectuais na história da infância. São Paulo, Cortez, 2002, p. 409458.

WOLLF, Silvia Ferreira Santos. Escolas para a república: os primeiros passos da Arquitetura das escolas públicas paulistas. São Paulo: USP, 2010.

TATIANE DE FREITAS ERMEL é estudante no curso de doutorado do Programa de Pós-Graduação em Educação da Pontifícia Universidade Católica do Rio Grande do Sul.

Endereço: Avenida Eduardo Prado, 1877 - casa 75 - 91751-000 - Porto Alegre - RS Brasil.

E-mail: tatiane.ermel@acad.pucrs.br.

Recebido em 10 de setembro de 2016.

Aceito em 23 de novembro de 2016. 